\title{
APORTE DE BIOMASSA E NUTRIENTES POR Allagoptera arenaria NA RESTINGA DA MARAMBAIA, RIO DE JANEIRO, RJ
}

\author{
Daniel Costa de Carvalho ${ }^{1}$, Marcos Gervasio Pereira ${ }^{2}$, Luís Fernando Tavares de Menezes ${ }^{3}$ \\ ${ }^{1}$ Eng. Agrônomo, M.Sc., PPGCAF UFRRJ, Seropédica, RJ, Brasil - daniel.florestal@yahoo.com.br. \\ ${ }^{2}$ Eng. Agrônomo, Dr., Depto. de Solos, Instituto de Agronomia, UFRRJ, Seropédica, RJ, Brasil - gervasio@ufrrj.br. \\ ${ }^{3}$ Biólogo, Dr., Centro Universitário Norte do Espírito Santo, UFES, São Mateus, ES, Brasil - 1tmenezes@ gmail.com. \\ Recebido para publicação 18/07/2012 - Aceito para publicação: 22/02/2014
}

\begin{abstract}
Resumo
O estudo avaliou a quantidade de matéria orgânica e nutrientes foliares aportados ao solo por Allagoptera arenaria em uma comunidade arbustiva de Palmae na restinga de Marambaia, Rio de Janeiro. As coletas foram realizadas em dez parcelas de $10 \mathrm{~m} \times 10 \mathrm{~m}\left(100 \mathrm{~m}^{2}\right)$, demarcadas aleatoriamente na formação arbustiva. Foram coletadas 3 (três) folhas de dez indivíduos adultos escolhidos aleatoriamente. Foi possível quantificar um incremento anual de massa seca de 8,2 Mg.ha ${ }^{-1}$ $\mathrm{ano}^{-1}$ para a área de estudo. Para o N, observou-se um teor de $12,3 \mathrm{~g} \cdot \mathrm{kg}^{-1}$, seguido de $5,7 \mathrm{~g} \cdot \mathrm{kg}^{-1}$ para o $\mathrm{K}$, os quais representam, respectivamente, um aporte de $303 \mathrm{~kg} \cdot \mathrm{N} \cdot \mathrm{ha}^{-1} \cdot$ ano $^{-1}$ e $140 \mathrm{~kg} \cdot \mathrm{K} \cdot \mathrm{ha}^{-1} \cdot$ ano $^{-1}$. Para P, foi verificado teor no material foliar na ordem de $0,31 \mathrm{~g} \cdot \mathrm{kg}^{-1}$, com aporte de $7,4 \mathrm{~kg} \cdot \mathrm{ha}^{-1} \cdot \mathrm{ano}^{-1}$. Palavra-chave: Ciclagem de nutrientes; ecossistemas costeiros; palmáceas; plantas focais.
\end{abstract}

\begin{abstract}
Biomass and Nutrient input by Allagoptera arenariain in Restinga da Marambaia, Rio de Janeiro, RJ. This research assessed the amount of organic matter and foliar nutrients in the soil from Allagoptera arenaria in a Palmae shrub community of Restinga da Marambaia, Rio de Janeiro. Samples were collected at ten randomly demarcated plots of $10 \times 10 \mathrm{~m}\left(100 \mathrm{~m}^{2}\right)$ in the bush. We collected three (3) leaves of ten randomly chosen adults. It was possible to quantify an annual increase of dry mass of $8,2 \mathrm{Mg} \mathrm{ha}^{-1} \mathrm{yr}^{-1}$ for the focused area. We observed for $\mathrm{N}$ an average grade of $12,3 \mathrm{~g} \mathrm{~kg}^{-1}$ followed by $5,7 \mathrm{~g} \mathrm{~kg}^{-1}$ for K, which respectively represent an investment of $303 \mathrm{~kg} \mathrm{~N} \mathrm{ha}^{-1}$ year ${ }^{-1}$ and $140 \mathrm{~kg} \mathrm{~K} \mathrm{ha}^{-1}$ year $^{-1}$. We observed for $\mathrm{P}$ mean levels in leaf material in order of $0,31 \mathrm{~g} \mathrm{~kg}^{-1}$ with intake of $7,4 \mathrm{~kg} \mathrm{ha}^{-1} \mathrm{year}^{-1}$.

Keywords: Nutrient cycling; coastal ecosystems; palms; nurse plants.
\end{abstract}

\section{INTRODUÇÃO}

O termo restinga, em seu sentido fitogeográfico, designa todas as formações vegetais que ocorrem sobre as planícies quaternárias litorâneas decorrentes da última regressão marítima (RONCARATI; MENEZES, 2005; SILVA; BRITEZ, 2005) e que foram colonizadas pela flora e fauna provenientes de ecossistemas adjacentes (ARAÚJO; LACERDA, 1987). As restingas correspondem a uma extensão de $70 \%$ do litoral brasileiro (ARAÚJO, 1992), cerca de $1.200 \mathrm{~km}^{2}$ (ARAÚJO; MACIEL, 1998) no estado do Rio de Janeiro.

Nas áreas de restinga, é comum encontrar solos com textura arenosa e uma baixa fertilidade natural, geralmente classificados como Neossolos Quartzarênicos (EMPRESA BRASILEIRA DE PESQUISA AGROPECUÁRIA (EMBRAPA), 2013). A baixa fertilidade natural desses solos é decorrente principalmente da acelerada decomposição da matéria orgânica, associada a uma alta lixiviação de nutrientes (VITOUSEK; SANFORD, 1986). Além da baixa fertilidade natural, essas áreas apresentam outros fatores limitantes ao crescimento vegetal, como grandes amplitudes térmicas, fortes ventos e elevada incidência solar (HAY; LACERDA, 1984; MENEZES; ARAÚJO, 2005b). Esses fatores condicionaram, ao logo do tempo, adaptações que permitiram a colonização e estabelecimento de espécies vegetais e animais nessas áreas (CHAPIN III, 1980). Algumas estratégias dos vegetais também podem ser observadas para minimizar o efeito desses fatores encontrados em ambientes de restinga, tais 
como elevados níveis de escleromorfismo, capacidade de translocação de nutrientes das plantas (MORAES; DOMINGOS, 1997; PIRES et al., 2006) e associações com fungos micorrízicos e bactérias fixadoras de nutrientes (OLIVEIRA et al., 2009).

Uma espécie típica das restingas brasileiras é a palmeira Allagoptera arenaria (Gomes) Kuntze (Arecaceae), cuja ocorrência se estende de Pernambuco até o Paraná (HENDERSON et al., 1995; MORAES, 1996), desde as mais preservadas até as mais impactadas (REIS, 2006). Possui altura variável entre 1 a 2,5 metros, caule tipo estipe, com cerca de $10 \mathrm{~cm}$ de diâmetro, normalmente indiviso e subterrâneo, podendo ramificar a partir de rizomas subterrâneos fazendo uso de reprodução assexuada (TOMLINSON, 1960; RIZZINI, 1979; LEITE, 1990; MENEZES, 1996; MENEZES; ARAÚJO, 1999). Possui uma alta capacidade de sobreviver ao fogo, rebrotando a partir dos rizomas subterrâneos (ARAÚJO; PEIXOTO, 1977; MENEZES, 1996; ALMEIDA; ARAÚJO, 1997; ZALUAR; SCARANO, 2001; MENEZES; ARAÚJO, 2004) e formando populações densas em determinados trechos do cordão arenoso, caracterizando a Formação Arbustiva de Palmae na restinga da Marambaia (MENEZES, 1996; MENEZES; ARAÚJO, 1999; 2000).

A contínua emissão de folhas é uma característica comum entre as palmeiras (HALLÉ et al., 1978), também sendo verificado um grande aporte desse material em áreas de restinga dominadas por $A$. arenaria (MENEZES; ARAÚJO, 1999; 2000; 2004). A densidade e biomassa aérea dessa espécie variam, em função de estarem estabelecidas sobre ou entre cordões litorâneos, sendo também influenciadas pelo nível do lençol freático e da distância do oceano (MENEZES; ARAÚJO, 1999). Por essas razões, tem se sugerido que A. arenaria seria uma espécie focal nas restingas, ou seja, fornecendo melhores condições para o estabelecimento de novas espécies nesses ambientes (ZALUAR, 1997; MENEZES; ARAÚJO, 1999; ZALUAR; SCARANO, 2001).

A identificação e caracterização das espécies focais em restingas é de suma importância para a compreensão da dinâmica da vegetação nesses ambientes (ZALUAR; SCARANO, 2001). Diversos estudos na Restinga da Marambaia vêm demonstrando a importância da ciclagem de nutrientes das formações vegetais para conservação e equilíbrio ecológico dos ambientes naturais (PEREIRA et al., 2008; PAULA et al., 2009; PEREIRA et al., 2012). No entanto, pouco se conhece sobre o aporte de biomassa e devolução de nutrientes das principais espécies estabelecidas em áreas de Formação Herbácea Fechada de Cordão Arenoso.

Portanto, este estudo fundamenta-se na hipótese de que a quantidade de matéria orgânica e nutrientes aportados por $A$. arenaria são de grande importância para as restingas, promovendo o estabelecimento de novas espécies nesses ambientes. Para testar essa hipótese, o presente trabalho teve como objetivo verificar se a $A$. arenaria reúne características de espécies focais em ambientes de restinga. Este trabalho visa ainda contribuir com o conhecimento da espécie e fornecer dados que auxiliem na conservação de ambientes de restinga.

\section{MATÉRIAL E MÉTODOS}

A área de estudo localiza-se na Restinga da Marambaia, no estado do Rio de Janeiro, compreendendo os municípios do Rio de Janeiro, Itaguaí e Mangaratiba, entre os paralelos $23^{\circ} 5^{\prime} 25^{\prime \prime} \mathrm{S}$ e $22^{\circ} 57^{\prime} 5^{\prime}$ S e meridianos $43^{\circ} 55^{\prime} 0^{\prime \prime} \mathrm{W}$ e $43^{\circ} 35^{\prime} 0^{\prime \prime} \mathrm{W}$ (Figura 1). A área da restinga utilizada neste experimento está sob concessão do Exército Brasileiro desde 1933.

A Formação Herbácea Fechada de Cordão Arenoso - Formação Pioneira de Influência Marinha (IBGE, 2012) - compreende uma faixa de areia com aproximadamente $49 \mathrm{~km}$ de extensão e cerca de 703,62 ha (MENEZES; ARAÚJO, 2005b). Essa formação é dominada por indivíduos de A. arenaria que recobrem as cristas praiais originadas pelas ondas de tempestades. O trecho estudado localiza-se na extremidade leste da restinga (município do Rio de Janeiro), entre a Estação Meteorológica e a Linha II (pertencentes ao Exército), aproximadamente $7 \mathrm{~km}$ a oeste da ponte que liga a restinga ao continente. Esse trecho, de fisionomia homogênea, foi estudado por Menezes e Araújo (2000), que estimaram a densidade total de A. arenaria em 12.272 ind.ha $^{-1}$.

Segundo classificação de Koeppen (1948), a Restinga da Marambaia é enquadrada no macroclima Aw (Tropical Chuvoso). A temperatura média anual é de $23,7^{\circ} \mathrm{C}$, sendo o mês de fevereiro o mais quente do ano (média de $26,8^{\circ} \mathrm{C}$ ) e agosto o mais frio (média de $20,9^{\circ} \mathrm{C}$ ). O climatograma obtido para a Restinga da Marambaia mostra que não ocorrem meses secos durante o ano, caracterizando o clima 
como super-úmido. A precipitação média anual é de $1.234 \mathrm{~mm}$, com $37 \%$ desse valor ocorrendo no verão, distribuídos em torno de 40 dias chuvosos. Os meses de inverno são os mais secos, quando ocorrem apenas $15 \%$ da precipitação média anual, distribuída ao redor de 21 dias (MATTOS, 2005).

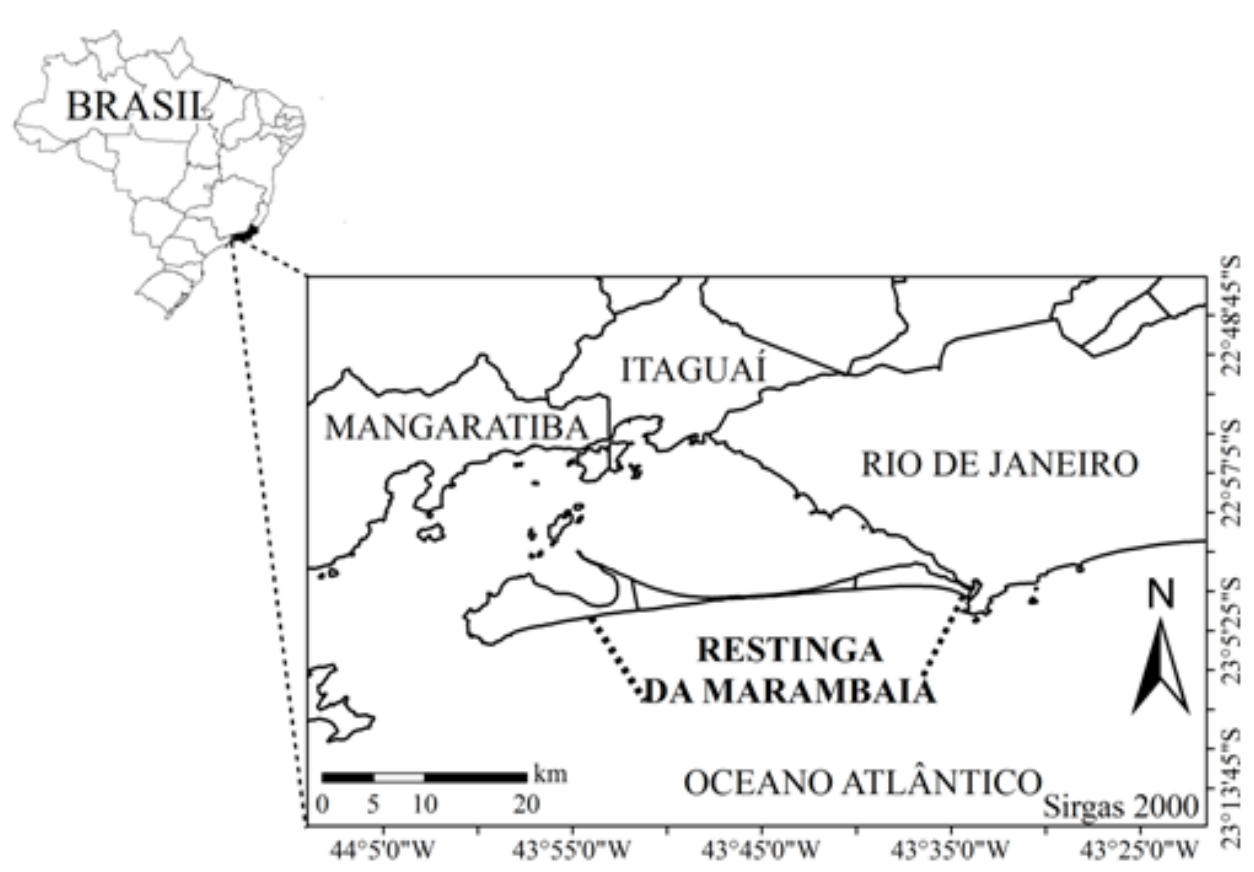

Figura 1. Localização da Restinga da Marambaia no estado do Rio de Janeiro, Brasil.

Figure 1. Locality of the Restinga da Marambaia, in Rio de Janeiro, Brazil.

Para a avaliação da produção de folhas, foram selecionados aleatoriamente 15 indivíduos na Formação Herbácea Fechada de Cordão Arenoso na Restinga da Marambaia. Os indivíduos foram avaliados bimensalmente, quanto à emissão de folhas, no período de janeiro de 2006 a janeiro de 2007. Para a determinação da composição química do material foliar, foram demarcadas 10 (dez) parcelas de $100 \mathrm{~m}^{2}$ (10 m x $10 \mathrm{~m}$ ), onde foram coletadas 3 (três) folhas de 10 (dez) indivíduos adultos escolhidos aleatoriamente nas parcelas. Procurou-se amostrar folhas em sua fase final de senescência, na qual podiam ser observadas as extremidades dos folíolos apresentando coloração amarelada e/ou seca, sem que estivessem em contato com o solo. O critério de seleção de indivíduos adultos foi a presença de estruturas reprodutivas (inflorescências e/ou infrutescências), sendo que elas foram excluídas das análises de nutrientes.

Após a coleta, as folhas foram cortadas manualmente e submetidas a secagem em estufa de circulação de ar forçado a $70{ }^{\circ} \mathrm{C}$ até atingirem massa constante. Em seguida o material foi triturado em moinho de facas tipo Willey e submetido a digestão sulfúrica (TEDESCO et al., 1995). No extrato foram determinados os conteúdos de nitrogênio $(\mathrm{N})$ por destilação por arraste a vapor, fósforo $(\mathrm{P})$ por colorimetria e potássio (K) por fotometria de chama. Para o cálculo do aporte de biomassa e nutrientes na formação vegetal estudada, foram utilizadas as informações disponibilizadas por Menezes e Araújo (2000), que quantificaram 859 indivíduos de A. arenaria em uma área de $700 \mathrm{~m}^{2}$ (12.272 ind.ha $\left.{ }^{-1}\right)$, posteriormente extrapolada para hectare.

\section{RESULTADOS E DISCUSSÃO}

A A. arenaria produziu anualmente $6,5( \pm 0,83)$ folhas em média por indivíduo. Já o incremento anual de massa seca proveniente dessa palmeira foi estimado em $8,2 \mathrm{Mg} \mathrm{ha}^{-1} \cdot$ ano $^{-1}$ para a área de estudo (Tabela 1). Esse valor encontra-se na faixa estabelecida para florestas situadas em latitudes de $25^{\circ}$, de 7 a 8,8 Mg.ha ${ }^{-1}$.ano ${ }^{-1}$ (BRAY; GORHAM 1964), e próximo aos valores encontrados para solos de baixa fertilidade natural (7,5 Mg.ha- ${ }^{-1} \cdot$ ano $^{-1}$ ) (ANDRADE et al., 1999) (Tabela 1). 
Tabela 1. Estimativa da serapilheira total produzida em alguns ecossistemas tropicais oligotróficos. Table 1. Estimate of total litter produced in some oligotrophic tropical ecosystems.

\begin{tabular}{lccc}
\hline Autor/ano & Tipologia vegetal & Local & $\begin{array}{c}\text { Mg.ha' } \\
\mathbf{a n o}^{-1}\end{array}$ \\
\hline Ramos e Pellens (1993) & Floresta de restinga & 6,2 \\
Moraes et al. (1999) & Floresta de restinga & RJ - Maricá & 3,9 \\
Britez et al. (2005) & Floresta de restinga & SP - Ilha do Cardoso & 5,2 \\
Pires et al. (2006) & Floresta inundável de restinga & PR - Ilha do Mel & 7,7 \\
Paula et al. (2009) & Restinga pós-praia & PR - Ilha do Mel & 5,1 \\
Pereira et al. 2012 & Floresta inundável de restinga & RJ - Restinga da & 11,1 \\
Este estudo & Floresta inundável de restinga & RJ - Restinga da & 7,6 \\
\hline
\end{tabular}

Embora este estudo reporte somente uma espécie, A. arenaria apresentou valores de produção de biomassa superiores a outras formações de restinga do Paraná, São Paulo e Rio de Janeiro (Tabela 1). Somente Paula et al. (2009) quantificaram valores superiores de aporte de biomassa $\left(11,1 \mathrm{Mg} \mathrm{ha}^{-1} \cdot \mathrm{ano}^{-1}\right)$, porém o estudo foi realizado em uma formação florestal de restinga com diferentes graus de saturação hídrica. $\mathrm{O}$ aporte de biomassa por A. arenaria foi duas vezes maior que o quantificado por Moraes et al. (1999) (3,9 Mg.ha ${ }^{-1} \cdot$ ano $\left.^{-1}\right)$ em uma formação semelhante na Ilha do Cardoso.

As diferenças encontradas da quantidade de serapilheira aportada entre os estudos podem ser condicionadas por fatores como a latitude (BRAY; GORHAM, 1964), altitude, precipitação (LONDSDALE, 1988) e evapotranspiração (MEENTEMEYER et al., 1978). Além desses, aspectos edáficos (VITOUSEK, 1984) e biológicos, como a estrutura (SCHLITTLER et al., 1993; WERNECK et al.; 2001), idade (LEITÃO FILHO et al., 1993) e composição florística da vegetação (SUNDARAPADIAN; SWAMY, 1999), também podem afetar a produtividade de serapilheira do sistema. Outro fator que pode influenciar nas comparações entre as áreas estudadas é a diferença entre os métodos utilizados. Porém convém salientar que diferentes coberturas vegetais apresentam características específicas, necessitando de adaptações dos métodos empregados. Neste estudo, por se tratar de uma palmeira arbustiva, não haveria a possibilidade da instalação de coletores de serapilheira. Sendo assim, procurou-se coletar as folhas na fase final de senescência, antes que tocassem o solo. Esse procedimento foi realizado para não haver perda de massa e nutrientes e, consequentemente, subestimação dos resultados.

Quanto aos teores de nutrientes foliares, verificou-se o maior valor para $\mathrm{N}\left(12,3 \mathrm{~g} \cdot \mathrm{kg}^{-1}\right)$, seguido de $\mathrm{K}\left(5,7 \mathrm{~g} \cdot \mathrm{kg}^{-1}\right)$ e em menor quantidade $\mathrm{P}\left(0,31 \mathrm{~g} \cdot \mathrm{kg}^{-1}\right)$ (Tabela 2). $\mathrm{O}$ aporte de $\mathrm{N}, \mathrm{P}$ e $\mathrm{K}$ foram, respectivamente, de $303 \mathrm{~kg} \cdot \mathrm{ha}^{-1}$.ano ${ }^{-1}, 7,4 \mathrm{~kg} \cdot \mathrm{ha}^{-1} \cdot$ ano $^{-1} \mathrm{e} 140 \mathrm{~kg} \cdot \mathrm{ha}^{-1} \cdot \mathrm{ano}^{-1}$. Esses valores são corroborados por outros estudos, concluindo que os teores obedecem à mesma sequência decrescente $(\mathrm{N}>\mathrm{K}>\mathrm{P})$ (Tabela 2). No geral, os teores de N, P e K da A. arenaria estão dentro da faixa observada para estudos de formações vegetais desenvolvidas em condições de oligotrofismo (Tabela 2).

$\mathrm{O}$ teor de $\mathrm{N}$ foi próximo a outros trabalhos de restinga (Tabela 2). Em ambientes de restingas secas, Moraes e Domingos (1997) e Britez et al. (1997) constataram teores de N de 13,0 g.kg-1 e 10,8 g. $\mathrm{kg}^{-1}$, respectivamente. A. arenaria aportou um valor de $\mathrm{N}\left(303 \mathrm{~kg} \cdot \mathrm{ha}^{-1} \cdot \mathrm{ano}^{-1}\right)$ maior que fragmentos de porte florestal na Restinga da Marambaia constatados por Paula et al. (2009) (130,8 kg.ha ${ }^{-1} \cdot$ ano $^{-1}$ ) e Pereira et al. (2012) (71,9 kg.ha ${ }^{-1} \cdot$ ano $\left.^{-1}\right)$. Todos esses estudos demonstraram que o nitrogênio é o elemento devolvido em maior quantidade, através do aporte de serapilheira (Tabela 2). O fornecimento de nitrogênio para o solo é de suma importância para a comunidade vegetal, visto que esse nutriente é essencial e mais exigido quantitativamente pela maioria das plantas (1,5\% da massa seca), estando relacionado diretamente ao metabolismo vegetal, tais como fotossíntese, respiração e crescimento (LARCHER, 2000).

Os altos valores de $\mathrm{N}$ para $A$. arenaria podem ser decorrentes de uma possível associação simbiótica da palmeira com bactérias fixadoras de nitrogênio (FBN). Braga (2008) constatou associação 
de bactérias fixadoras de nitrogênio na rizosfera de A. arenaria na mesma área do presente estudo. O mesmo autor inferiu que essa associação seja uma vantagem adaptativa da palmeira no ambiente, mantendo suas folhas verdes e vistosas independentemente da época do ano e das condições climáticas. Carvalho (1997) também observou a presença de bactérias fixadoras de nitrogênio dos gêneros Azospirillum sp. e Herbaspirillum sp. associadas às palmeiras dendezeiro (Elaeis guineensis Jacq.) e pupunheira (Bactris gasipaes H. B. K.), em vários tipos de solos florestais. Esses autores salientam ainda a importância dessa associação de FBN para essas palmeiras, já que elas se estabelecem em solos de baixa fertilidade.

Tabela 2. Concentrações médias $\left(\mathrm{g} \cdot \mathrm{kg}^{-1}\right)$ dos macronutrientes foliares de outras formações vegetais tropicais.

Table 2. Average concentrations $\left(\mathrm{g}^{\mathrm{kg}} \mathrm{kg}^{-1}\right)$ of leaf macronutrients at other tropical vegetation.

\begin{tabular}{|c|c|c|c|c|c|c|}
\hline Autor/ano & Tipologia vegetal & Local & $\begin{array}{l}\text { N de } \\
\text { spp. }\end{array}$ & $\mathbf{N}$ & $\mathbf{P}$ & $\mathbf{K}$ \\
\hline Peace e Macdonald, 1981 & Restinga & Malásia & 9 & 8,7 & 0,22 & 3,5 \\
\hline Thompson et al., 1992 & Ombrófila Densa das Terras Baixas & Roraima & 77 & 18,8 & 1,20 & 10,3 \\
\hline \multirow[t]{2}{*}{ Moraes e Domingos, 1997} & Ombrófila Densa das Terras Baixas & São Paulo & 10 & 31,7 & 1,0 & 10,8 \\
\hline & Restinga & & 10 & 13,0 & 0,60 & 3,5 \\
\hline \multirow{2}{*}{ Britez et al., 1997} & Restinga paludosa & Paraná & 9 & 14,4 & 0,41 & 5,2 \\
\hline & Restinga seca & & 10 & 10,8 & 0,31 & 5,1 \\
\hline \multirow[t]{3}{*}{ Boeger et al., 2005} & $\begin{array}{c}\text { Ombrófila Densa das Terras Baixas } \\
\text { Estádio inicial }\end{array}$ & Paraná & 4 & 11,8 & 0,28 & 3,2 \\
\hline & Estádio intermediário & & 8 & 12,0 & 0,21 & 4,3 \\
\hline & Estádio avançado & & 11 & 14,0 & 0,24 & 5,2 \\
\hline \multirow{2}{*}{$\begin{array}{l}\text { Paula et al., } 2009 \\
\text { Este estudo }\end{array}$} & Floresta inundável de restinga & Rio de Janeiro & 42 & 12,0 & 1,13 & 3,49 \\
\hline & $\begin{array}{l}\text { Restinga }-A \text {. arenaria } \text { em } \\
\text { comunidade de cordão arenoso }\end{array}$ & Rio de Janeiro & 1 & 12,3 & 0,31 & 5,70 \\
\hline
\end{tabular}

Os baixos teores de P no tecido de A. arenaria devem-se ao fato de esse nutriente apresentar-se quase sempre em baixas concentrações em solos de formações vegetais tropicais (WARING; SCHLISINGER, 1985). Embora o teor de P de A. arenaria esteja abaixo dos valores encontrados para restingas brasileiras (MORAES; DOMINGOS, 1997; PAULA et al., 2005), esse nutriente ainda se encontra dentro da faixa média observada em áreas de formações vegetais desenvolvidas em condições de oligotrofismo (Tabela 2).

Mesmo em solos de baixa fertilidade natural, como os de restinga, os teores de $\mathrm{P}$ observados para A. arenaria podem ser resultado da associação da palmeira com fungos micorrízicos arbusculares (FMA). Braga (2008) identificou 13 espécies de FMA com uma colonização média de 68,2\% na rizosfera de A. arenaria na Formação Fechada de Cordão Arenoso na Restinga da Marambaia. O mesmo autor salientou a importância dessa associação no aumento de captação desse nutriente pela planta. Oliveira $e t$ al. (2009) também constataram que os FMA aumentam a obtenção de nutrientes pelas plantas, sendo um processo fundamental para o desenvolvimento inicial e estabelecimento vegetal em áreas revegetadas de restingas.

A principal função do $\mathrm{P}$ nas plantas é o seu envolvimento na estocagem de energia, através da alta energia das ligações do P, encontradas na ATP. Por essa razão, o P é essencial para todas as transformações de energia (HAAG, 1985). $\mathrm{O}$ retorno de $\mathrm{P}$ pela A. arenaria na restinga facilitaria o estabelecimento de outras espécies, haja vista que muitas delas dependem desse nutriente principalmente na fase inicial de desenvolvimento (HAAG, 1985). Embora as concentrações de P em A. arenaria sejam inferiores às de outros estudos, provavelmente o retorno desse nutriente para o ambiente deve-se principalmente a essa espécie, devido a sua representatividade na Formação Fechada de Cordão Arenoso na Restinga da Marambaia (MENEZES et al., 1999; 2000; 2004).

$\mathrm{O}$ teor de potássio de observado na área de A. arenaria $\left(5,70 \mathrm{~g} \cdot \mathrm{kg}^{-1}\right)$ foi relativamente maior quando comparado ao das demais áreas de restingas (Tabela 2). Os valores de $\mathrm{K}$ mais próximos ao do presente estudo foram constatados por Britez et al. (1997). Os autores observaram teores de K da 
serapilheira entre 5,2 g.kg-1 e 5,1 g. $\mathrm{kg}^{-1}$, respectivamente, em dois tipos de restinga, uma paludosa e outra seca.

Os altos teores de potássio em A. arenaria podem ser decorrentes das altas concentrações desse nutriente nos solos de restinga (referência) decorrentes da constante deposição da salsugem (maresia) pelo oceano (HAY; LACERDA, 1984). Esse nutriente tem um papel fundamental na adaptação das espécies como a A. arenaria, que se estabelecem em locais inóspitos (restingas). As adaptações ligadas ao potássio são principalmente o desenvolvimento radicular, a regulação da pressão osmótica e a abertura e fechamento dos estômatos (LARCHER, 2000).

Ratificando o contexto acima, os principais limitadores do estabelecimento de espécies vegetais nas restingas são a dessecação - das sementes e estruturas vegetativas - e baixos níveis de nutrientes desses solos (MAUN, 1994; ZALUAR; SCARANO, 2001). Nesse sentido, as espécies "focais" desenvolvem um papel fundamental na manutenção estrutural e na sucessão vegetal nesses ambientes, contribuindo na melhoria das condições para a germinação de sementes, estabelecimento e/ou crescimento de outras espécies vegetais (ZALUAR; SCARANO, 2001). Algumas das melhorias fornecidas pelas espécies "focais" são o aporte de biomassa, nutrientes, sombreamento e retenção de umidade (ZALUAR; SCARANO, 2001).

Procurando identificar e entender as espécies "focais" em restinga, Zaluar e Scarano (2001) constataram uma alta associação de Pilosocereus arrabidae (Cactaceae) com A. arenaria $\left(\mathrm{x}^{2}=25,014\right.$, $\mathrm{n}=738, \mathrm{p}<0,001)$ no Parque Nacional de Jurubatiba. Os mesmos autores reconheceram essa associação por não verificarem indivíduos de $P$. arrabidae em solo desnudo de restinga, encontrando condições ideais para o seu desenvolvimento sob a copa da A. arenaria. Zaluar (1997) encontrou A. arenaria em 97\% $(\mathrm{n}=238)$ das moitas de vegetação num trecho de restinga no Parque Nacional de Jurubatiba, sugerindo que a palmeira seria uma das principais espécies vegetais formadoras das moitas da região. Por essas características, têm-se sugerido que A. arenaria seria uma planta "focal" para ambientes de restinga, participando efetivamente na agregação de outras espécies (ZALUAR, 1997; ZALUAR; SCARANO, 2001).

\section{CONCLUSÃO}

- O material foliar depositado por A. arenaria contribuiu com uma adição significativa de biomassa e nutrientes para o sistema de restinga. Em solos de baixa fertilidade natural, como os de restinga, essa contribuição pode auxiliar na melhoria dos atributos físicos e químicos do solo.

- Devido a sua dominância e representatividade na Formação Fechada de Cordão Arenoso na Restinga da Marambaia, a A. arenaria é, provavelmente, a principal espécie vegetal fornecedora de matéria orgânica e nutrientes para essa fitofisionomia. Sendo assim, verifica-se que A. arenaria reúne características de plantas focais, ou seja, propicia melhores condições ao ambiente para a entrada e estabelecimento de outras espécies, tanto vegetais quanto animais.

\section{AGRADECIMENTOS}

Ao Campo de Provas da Marambaia (CPrM), pelo consentimento da pesquisa e apoio logístico, e à Fundação $\mathrm{O}$ Boticário, pelo auxílio financeiro.

\section{REFERÊNCIAS}

ALMEIDA, A. L.; ARAÚJO, D. S. D. Comunidades vegetais do cordão arenoso externo da Reserva Ecológica Estadual de Jacarepiá, Saquarema, RJ. Oecologia Brasil, v. 3, p. 45 - 61, 1997.

ANDRADE, A. G.; CABALlERO, S. S. U.; FARIA, S. M. Ciclagem de nutrientes em ecossistemas florestais. Rio de Janeiro: Embrapa Solos. Documentos, n. 13, 1999.

ARAÚJO, D. S. D.; PEIXOTO, A. L. Renovação de uma comunidade vegetal de restinga após queimada. In CONGRESSO NACIONAL DE BOTÂNICA, 27., 1977, Rio de Janeiro. Anais da Academia Brasileira de Ciências. Rio de Janeiro. 1977. p. 1 - 17. 
ARAÚJO, D. S. D.; LACERDA, L. D. A Natureza das Restingas. Ciência Hoje, v. 6, n. 33, p. 42 - 48, 1987.

ARAÚJO, D. S. D. Vegetation types of sandy coastal plains of tropical Brazil: a first approximation. In: SEELIGER, U. Coastal Plant Communities of Latin America. New York, p. 337 - 347, 1992.

ARAÚJO, D. S. D.; MACIEL, N. C. Restingas Fluminenses: Biodiversidade e Preservação. Boletim FBCN, v. 25, p. 27 - 71, 1998.

BOEGER, M. R. T.; WISNIEWSKI, C.; REISSMANN, C. B. Nutrientes foliares de espécies arbóreas de três estádios sucessionais de floresta ombrófila densa no sul do Brasil. Acta Botânica Brasílica, v. 19, n. 1 , p. $167-181,2005$.

BOVI, M. L. A.; GODOY-JÚNIOR, G.; COSTA, E. A. D.; BERTON, R. S.; SPIERING; S. H.; VEJA, F. V. A.; CEMBRANELLI, M. A. R.; MALDONADO, C. A. B. Lodo de esgoto e produção de palmito em pupunheira. Revista Brasileira de Ciência do Solo, v. 31, n. 1, p. 153 - 166, 2007.

BRAGA, T. V. S. Associações com fungos micorrízicos e bactérias fixadoras de nitrogênio em Allagoptera arenaria (Gomes) O. Kuntze na Restinga de Marambaia, RJ. (Monografia) Universidade Federal Rural do Rio de Janeiro, Seropédica, 2008.

BRAY, J. R.; GORHAM, E. Litter production in the forests of the world. Advances in Ecological Research, v. 2, p. 101 - 157, 1964.

BRITEZ, R. M.; REISSMANN, C. B.; SILVA, S. M.; ATHAYDE, S. F.; LIMA, R. X. B.; QUADROS, R. M. Chemical characterization of two forests on the coastal plains of the Ilha do Mel, Paraná, Brazil. Developments in Plants and Soil Sciences, v. 78, p. 461 - 462, 1997.

BRITEZ, R. M.; PIRES, L. A.; REISSMANN, C. B.; PAGANO, S. N.; SILVA, S. M.; ATHAYDE, S. F.; LIMA, R. X. Ciclagem de nutrientes na planície costeira. In: MARQUES, M. C. M.; BRITEZ R. M. História Natural e Conservação da Ilha do Mel. Curitiba, Editora da Universidade Federal do Paraná, 2005. p. 145 - 168.

CARVALHO, A. L. V. Associação de bactérias diazotróficas e fungos micorrízicos arbusculares em mudas de pupunheira (Bactris gasipaes H. B. K.) e de dendezeiro (Elaeis guineenses Jacq.). Dissertação (Mestrado) - Universidade Federal Rural do Rio de Janeiro, Seropédica, 1997.

CHAPIN III, F. S. The mineral nutrition of wild plants. Annual Review of Ecology and Systematics, v. 11, p. $233-240,1980$.

EMPRESA BRASILEIRA DE PESQUISA AGROPECUÁRIA (EMBRAPA). Sistema Brasileiro de Classificação de Solos. 3. ed. Brasília, 2013. 353 p.

HAAG, H. P. Ciclagem de nutrientes em florestas tropicais. Campinas: Fundação Cargill, 1985. 144 p.

HALlÉ, F., OLDEMAN, R. A. A.; TOMLINSON, P. B. Tropical trees and forests: an architectural analysis. Springer-Verlang, 1978. $441 \mathrm{p}$.

HAY, J. D.; LACERDA, L. D. Ciclagem de nutrientes no ecossistema de restinga. In: LACERDA, L. D.; ARAÚJO, D. S. D.; CERQUEIRA R.; TURCQ, B. Restingas: Origem, Estrutura, Processos. Editora CEUFF, Niterói, 1984. p. 459 - 475.

HENDerson, A.; Galeano, G. E; Bernal, R. Field Guide to the Palms of the Americas. Princeton University Press, New Jersey, 1995. 162 p.

KOEPPEN, W. Climatología. Fondo de Cultura Económica, México, 1948. 466 p.

LARCHER, W. Ecofisiologia Vegetal. São Carlos, RiMa. São Paulo, 2000. 531 p.

LEITÃO-FILHO, H. F.; PAGANO, S. N.; CESAR, O.; TIMONI, J. L.; RUEDA, J. J. Ecologia da Mata Atlântica em Cubatão. Editora da Universidade Estadual Paulista e Editora da Universidade Estadual de Campinas, São Paulo e Campinas, 1993. 
LEITE, C. O. Biologia de reprodução de Allagoptera arenaria (Gomes) O. Kuntze (Diplothemium maritimum Mart.) - Palmae. Dissertação (Mestrado) - Universidade Federal do Rio de Janeiro, Rio de Janeiro, 1990.

LONDSDALE, W. W. Predicting the amount of litterfall in forests of the world. Annals of Botany, v. 61, n. 3, p. 319 - 324, 1988.

MAGAT, S. S. Fertilizer recomendations for coconut based on soil and leaf analyses. Philippine Journal of Coconut Studies, v. 16, p. 25 - 30, 1991.

MATTOS, C. C. L. V. Caracterização climática da restinga da Marambaia. In: MENEZES, L. F. T.; PEIXOTO, A. L.; ARAÚJO, D. S. D. História Natural da Marambaia. Editora da Universidade Federal Rural do Rio de Janeiro, Seropédica, 2005. p. 55 - 66.

MAUN, M. A. Adaptation enhancing survival and establishment of seedlings on coastal dune systems. Vegetatio, v. 111, p. 59 - 70, 1994.

MEDINA, J. C.; GARCIA, J. L. M.; MARTIN, Z. J.; KATO, K.; TERUO, P.; TURATTI, J. M.; SANTOS, L. C.; SILVA, M. T. C.; CANTO, W. L.; BICUDO NETO, L. C.; MORETTI, V. A. Coco: da cultura ao processamento e comercialização. Campinas: Série frutas tropicais n. 5, Instituto de Tecnologia de Alimentos, 1980. 285 p.

MEENTEMEYER, V. Macroclimate and lignin control of litter decomposition rates. Ecology, v. 59, n. 3, p. 465 - 472, 1978.

MENEZES, L. F. T. Caracterização de comunidades vegetais praianas da Restinga da Marambaia, RJ. Dissertação (Mestrado) - Universidade Federal Rural do Rio de Janeiro, Seropédica, 1996.

MENEZES, L. T. F.; ARAÚJO, D. S. D. Estrutura de duas formações vegetais no cordão externo da Restinga da Marambaia, RJ. Acta Botânica Brasílica, v. 13, n. 2, p. 223 - 235, 1999.

MENEZES, L. F. T.; ARAÚJO, D. S. D. Variação da biomassa aérea de Allagoptera arenaria (Gomes) O. Kuntze (Arecaceae) em uma comunidade arbustiva de Palmae na Restinga de Marambaia, RJ. Revista Brasileira de Botânica, v. 60, n. 1, 2000.

MENEZES, L. F. T.; ARAÚJO, D. S. D. Regeneração e riqueza da formação arbustiva de Palmae em uma cronossequência pós-fogo na Restinga da Marambaia, Rio de Janeiro, RJ, Brasil. Acta Botânica Brasílica, v. 18, n. 4, p. 771 - 780, 2004.

MENEZES, L. F. T.; PEIXOTO, A. L.; ARAÚJO, D. S. D. História Natural da Marambaia. Seropédica: Edur, 2005a. 288 p.

MENEZES, L. F. T.; ARAÚJO, D. S. D. Formações Florestais da restinga da Marambaia. In: MENEZES, L. F. T.; PEIXOTO, A. L.; ARAÚJO, D. S. D. História Natural da Marambaia. Editora da Universidade Federal Rural do Rio de Janeiro, Seropédica, 2005b. p. 67 - 120.

MORAES, M. R. Allagoptera (Palmae). New York, The New York Botanical Garden, 1996.

MORAES, R. M.; DOMINGOS, M. Elementos minerais em folhas de espécies arbóreas de Mata Atlântica e Mata de Restinga, na Ilha do Cardoso, SP. Revista Brasileira de Botânica, v. 20, n. 2, p. 133 - 138, 1997.

MORAES, R. M.; DELITTI, W. B. C.; DE VUONO, Y. S. Litterfall and litter nutrient content in two brazilian tropical forests. Revista Brasileira de Botânica, v. 22, n. 1, p. 9 - 16, 1999.

NEVES, E. J. M.; SANTOS, A. F.; KALIL FILHO, A. N.; MARTINS, E. G. Teores de nitrogênio, fósforo e potássio nas folhas de pupunha plantada no litoral do estado do Paraná. Colombo: Embrapa Florestas, n. 71, 2002.

OLIVEIRA, J. R. G.; SOUZA, R. G.; SILVA, F. S. B.; MENDES, A. S. M.; YANO-MELO, A. M. O papel da comunidade de fungos micorrízicos arbusculares (FMA) autóctones no desenvolvimento de 
espécies vegetais nativas em área de dunas de restinga revegetadas no litoral do estado da Paraíba. Revista Brasileira de Botânica, v. 32, n. 4, p. 663 - 670, 2009.

PAULA, R. R.; PEREIRA, M. G.; MENEZES, L. F. T. Aporte de nutrientes e decomposição da serapilheira em três fragmentos florestais periodicamente inundados na Ilha da Marambaia, RJ. Ciência Florestal, Santa Maria, v. 19, p. 139 - 148, 2009.

PEACE, W. J. H.; MACDONALD, F. D. An investigation of the leaf anatomy, foliar mineral levels, and water relations of trees of a Sarawak Forest. Biotropica, Lawrence, v. 13, n. 2, p. 100 - 109, 1981.

PEREIRA, M. G.; MENEZES, L. F. T.; SCHULTZ, N. Aporte e decomposição da serapilheira na floresta Atlântica, Ilha da Marambaia, Mangaratiba, RJ. Ciência Florestal, Santa Maria, v. 18, n. 4, p. 443 - 454, 2008.

PEREIRA, M. G.; SILVA, A. N.; PAULA, R. R.; MENEZES, L. F. T. Aporte e decomposição de serapilheira em Floresta Periodicamente Inundável na Restinga da Marambaia, RJ. Ciência Florestal, v. 22, n. 1, p. 59 - 67, 2012.

PIRES, L. A.; BRITEZ R. M. Produção, acúmulo e decomposição da serapilheira em uma restinga da Ilha do Mel, Paranaguá, PR, Brasil. Acta Botânica Brasílica, São Paulo, v. 20, n. 1, 2006.

RAMOS, M. C. L.; PELLENS, R. Produção de serapilheira em ecossistema da restinga de Maricá, Estado do Rio de Janeiro. In: SIMPÓSIO DE ECOSSISTEMAS DA COSTA BRASILEIRA, 3., 1993, Serra Negra. Anais..., 1993. p. 89 - 98.

REIS, R. C. C. Palmeiras (Arecaceae) das restingas do Estado do Rio de Janeiro, Brasil. Acta Botânica Brasílica, São Paulo, v. 20, n. 3, 2006.

REISSMANN, C. B.; SANTOS FILHO, A.; ROCHA, H. O. Sistematização da palma de palmito (Euterpe edulis Mart.) para fins de avaliação nutricional. In: ENCONTRO NACIONAL DE PESQUISADORES EM PALMITO, 1988, Curitiba. Anais..., Curitiba, 1988, p. 91 - 104.

RIZZINI, C. T. Tratado de fitogeografia do Brasil: aspectos sociológicos e florísticos. São Paulo: HUCITEC-EDUSP. 1979. v. 2.

ROGNON, F. Cocotier. In: MARTIN-PRÉVEL, P.; GAGNARD, J.; GAUTIER, P. L'analyse végétale dans le contrôle de l'alimentation des plantes tempérées et tropicales. Paris: TeceDoc, 1984. p. 447 457.

RONCARATI, H.; MENEZES, L. F. T. Marambaia, Rio de Janeiro: origem e evolução. In: MENEZES, L. F. T.; PEIXOTO, A. L.; ARAÚJO, D. S. D. História Natural da Marambaia. Editora da Universidade Federal Rural do Rio de Janeiro, Seropédica, 2005. p. 15 - 38.

RUIZ-FILHO, R. R.; MARQUES, R.; ROCHA, A. A. Crescimento e aspectos nutricionais da Palmeira Real Australiana, sob diferentes espaçamentos, no litoral do Paraná, Brasil. Scientia Agraria, Curitiba, v. 11, n. 2, p. 175 - 180, 2010.

SCHLITTLER, F. H. M.; MARINIS, G.; CÉSAR, O. Produção de serapilheira na floresta no Morro do Diabo, Pontal de Paranapanema, São Paulo. Naturalia, v. 18, p. 135 - 147, 1993.

SILVA, S. M.; BRITEZ, R. M. A vegetação da planície costeira. In: MARQUES, M. C. M.; BRITEZ, R. M. História Natural e Conservação da Ilha do Mel. Curitiba, Editora da Universidade Federal do Paraná. 2005. p. 49 - 84.

SOBRAL, L. F. Nutrição e adubação do coqueiro. In: FERREIRA, J. M. S.; WARWICK, D. R. N.; SIQUEIRA, L. A. A cultura do coqueiro no Brasil. Aracaju, Embrapa, 1998. p. 129 - 157.

SUNDARAPADIAN, S. M.; SWAMY, P. S. Litter production and leaf-litter decomposition of selected tree species in tropical forests at Kodayar in the Western Ghats, India. Forest Ecology and Management v. 123 , p. $231-244.1999$. 
TEDESCO, M. J.; GIANELlO, C.; BISSANI, C. A.; BOHNEN, H.; VOLKWEISS, S. J. Análises de solo, plantas e outros materiais. Boletim Técnico, Porto Alegre, Editora da Universidade Federal do Rio Grande do Sul. n. 5. 1995.

TELES, H. F.; REZENDE, C. F. A.; LEANDRO, W. M.; PIRES, L. L.; TAVARES, P. V. A.; SANTOS, R. A. S. G. Teores de nutrientes em folhas de Macaúba (Acrocomia aculeata) em diferentes estádios fenológicos no cerrado goiano. In: SIMPÓSIO NACIONAL DO CERRADO, 9., 2008, Brasília. Anais... Brasília. 2008.

THOMPSON, J.; PROCTOR, J.; VIANA, V.; MILLIKEN, W.; RATTER, J. A.; SCOTT, D. A. Ecological studies on a lowland evergreen rain forest on Maracá Island, Roraima, Brazil. Journal of Ecology, v. 80, p. 689 - 703, 1992.

TOMLINSON, P. B. Essays on the morphology of palms. The early growth of the palm. Principes, v. 4, n. 4, p. 140 - 143, 1960.

TURNER, I. M.; ONG, B. L.; TAN, H. T. W. Vegetation analysis, leaf structure and nutrient status of a Malaysian health community. Biotropica, v. 27, n. 1, p. 2 - 12, 1995.

VITOUSEK, P. M. Litterfall, nutrient cycling and nutrients in tropical forests. Ecology, v. 65, n. 1, p. 285 - 298, 1984.

VITOUSEK. P.; SANFORD, R. Nutrient cycling in moist tropical forest. Annual Review on Ecology Systematics, Palo Alto, v. 17, p. 137 - 167, 1986.

WARING, R. H.; SCHLISINGER, W. H. Forest Ecosystems: Concepts and management. Orlando: Academic Press, Inc. Harcourt Brace Jovanovich Publishers, 1985.

WERNECK, M. S.; PEDRALLI, G.; GIESEKE, L. F. Produção de serapilheira em três trechos de uma Floresta Semidecídua com diferentes graus de perturbação na Estação Ecológica do Tripuí, Ouro Preto, Mg. Revista Brasileira de Botânica, v. 24, n. 2, p. 195 - 198, 2001.

ZALUAR, H. L. T. Espécies focais e a formação de moitas na restinga aberta de Clusia, Carapebus, RJ. Dissertação (Mestrado) - Universidade Federal do Rio de Janeiro, Rio de Janeiro, 1997.

ZALUAR, H. L. T.; SCARANO, F. R. Facilitação em restingas de moitas: Um século de buscas por espécies focais. In: ESTEVES, F. A.; LACERDA, L. D. Ecologia de restingas e lagos costeiros. Macaé, NUPEM/UFRJ, 2001. p. 3 - 23. 